Pak. j. sci. ind. res. Ser. B: biol. sci. 201356 (1) 18-22

\title{
Genetic Divergence Analysis in Pumpkin
}

\author{
Abul Khair Muhammad Quamruzzaman ${ }^{a *}$, Shahabuddin Ahmad, Mohammad Moniruzzaman', \\ Mohammad Khalid Jamil ${ }^{\mathrm{c}}$ and Mohammad Amir Hossain Mollah ${ }^{\mathrm{d}}$ \\ ${ }^{a}$ Olericulture Division, Horticulture Research Centre, Bangladesh Agricultural Research Institute, \\ Gazipur-1701, Bangladesh

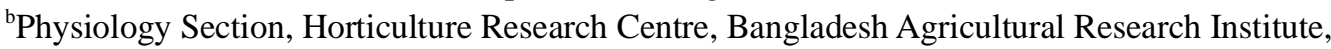 \\ Gazipur-1701, Bangladesh \\ ${ }^{\mathrm{c}}$ Training and Communication Division, Bangladesh Agricultural Research Institute, \\ Gazipur-1701, Bangladesh \\ dUniconsult International Ltd., Building-1, Sector-6, Road no.-16, Uttara, Dhaka-1230, Bangladesh
}

(received June 9, 2011; revised January 5, 2012; accepted January 30, 2012)

\begin{abstract}
Genetic divergence among 18 pumpkin genotypes was estimated using Mahalanobis's $\mathrm{D}^{2}$ statistic. Altogether four clusters were formed where cluster I contained the highest number of genotypes (8) and cluster II contained the lowest (1). The highest intra-cluster distance was observed for cluster I (0.831) and the lowest for cluster IV (0.651). The highest inter-cluster distance was observed between cluster I and II (24.346). Cluster II recorded the highest mean for fruit number/plant, TSS, fruit yield and minimum in cavity length and cavity diameter. Cluster III had the second highest mean for fruit diameter, fruit number/plant, individual fruit weight, fruit yield and the fewest number of days to $1^{\text {st }}$ female flowering, earliness being a desirable trait. These crosses may produce new recombinants with desirable traits.
\end{abstract}

Keywords: genetic diversity, pumpkin, cluster analysis

\section{Introduction}

Pumpkin (Cucurbita moschata Duch.) is one of the most important vegetables in Bangladesh which ranks next to brinjal, radish and arum in total acreage and annual production. The national average yield is 7.73 t/ha (BBS, 2008), which is very low. Pumpkin is very nutritious due to its high content of vitamin A. Central Mexico is considered as centre of origin of pumpkin and now is widely grown in most tropical countries. It belongs to the botanical family Cucurbitaceae.

Information on genetic divergence among the available germplasm is vital to a plant breeder for an efficient choice of parents for hybridization. Genetically diverse parents are likely to contribute desirable segregants. Crosses between diverse parents are more likely to result in high heterotic $F_{1} s$ and a broad spectrum of variability in the segregating generation (Arunachalam, 1981). Improvement in fruit yield and quality is normally achieved by selecting genotypes with desirable character combinations existing in nature or by hybridization. Selection of parents identified on the basis of divergence analysis would be more promising for a hybridization

*Author for correspondence; E-mail: akmqzs@gmail.com programme. Some related results have been reported by Masud et al. (1995) in pumpkin, Quamruzzaman (2008a) in bitter gourd and Quamruzzaman et al. (2008b) in ridge gourd. Information on the selection of local pumpkin genotypes on the basis of diversity is inadequate in Bangladesh. Therefore, the present investigation was undertaken to estimate the nature and magnitude of genetic diversity in some local pumpkin genotypes under Bangladesh conditions.

\section{Materials and Methods}

The experiment was conducted at the experimental field of Olericulture Division, Horticulture Research Centre (HRC), Bangladesh Agricultural Research Institute- Gazipur, during the winter season of 200506 . The seeds of 18 selected advanced pumpkin lines were sown on the polybag on $25^{\text {th }}$ October, 2005. Twenty day old seedlings were transplanted in the main field on $15^{\text {th }}$ November 2005. The experiment was laid out in a RCB design with three replications. The unit plot size was $10.0 \times 2.0 \mathrm{~m}$ maintaining 2.0 $\times 2.0 \mathrm{~m}$ spacing. The land was fertilized with cow dung, urea, triple super phosphate (TSP) murate of potash (MP) gypsum and zinc @ 20000, 175, 175, 
150, 100 and $12 \mathrm{~kg} / \mathrm{ha}$, respectively. Total amount of cow dung, TSP, gypsum and zinc and $1 / 3^{\text {rd }}$ of each of urea and MP were applied during final land preparation and in the pit. The rest of urea and MP were applied in four equal installments at 21, 35, 55 and 75 days after transplanting. The intercultural operations (weeding and irrigation etc.) were done as and when necessary. Data on days to $1^{\text {st }}$ female flowering, fruit length $(\mathrm{cm})$, fruit diameter $(\mathrm{cm})$, fruit number, individual fruit weight $(\mathrm{kg})$, cavity length $(\mathrm{cm})$, cavity diameter $(\mathrm{cm})$, flesh thickness $(\mathrm{cm})$, total soluble solute (TSS) (\%), fruit yield (t/ha), flesh colour, fruit skin colour, fruit shape and crispiness were recorded from three randomly selected plants per entry per replication. Plot means over the replications were used for the statistical analysis. Genetic diversity was studied following Mahalanobis's (1936) generalized distance $\left(D^{2}\right)$ extended by Rao (1952). Based on the $D^{2}$ values, the genotypes were grouped into clusters following the method suggested by Tocher (Rao, 1952). Intra and inter cluster distances and principal coordinated analysis (PCA) were calculated by the methods of Singh and Chaudhury (1985). Statistical analyses were carried out using Genstat 5 software.

\section{Results and Discussion}

The analysis of variance showed significant differences among the 18 genotypes for all 10 characters under study indicating the presence of notable genetic variability among the genotypes. Eighteen genotypes were grouped into four clusters on the basis of cluster analysis. Cluster I contained 8 lines, followed by 5 in cluster IV and 4 in cluster III. Cluster II was composed of only one genotype (Table 1).

The maximum inter-cluster distance was recorded between the cluster I and II (24.346) followed by the distance between I and III (17.298) (Table 2). As the genetic variation is very distinct among the groups, hybridization among genotypes from these four clusters may produce a wide spectrum of segregating populations. The lowest inter cluster distance was observed between cluster III and IV (6.515) followed by II and III (7.358) suggesting a close relationship among these three clusters. However, the intra-cluster divergence varied from 0.651 to 0.831 , maximum being from cluster I comprised of eight genotypes, while the minimum distance was observed in cluster IV comprised of five genotypes.

Table 1. Distribution of 18 genotypes of pumpkin in different clusters

\begin{tabular}{|c|c|c|c|c|c|c|c|}
\hline Clusters & $\begin{array}{l}\text { Number of } \\
\text { genotypes }\end{array}$ & Genotypes & Accession no. & $\begin{array}{l}\text { Flesh } \\
\text { colour }\end{array}$ & $\begin{array}{l}\text { Fruit skin } \\
\text { colour }\end{array}$ & Fruit shape & Crispiness \\
\hline \multirow[t]{8}{*}{ I } & \multirow[t]{8}{*}{8} & 3 & PKN12-5-2 & DO & $\mathrm{B}+\mathrm{G} \& \mathrm{Y}$ & VF & $\mathrm{NC}$ \\
\hline & & 4 & PKN12-5-4 & LO & $\mathrm{LY}+\mathrm{Y}$ & $\mathrm{F}$ & $\mathrm{NC}$ \\
\hline & & 5 & PKN15-1-1 & DO & $\mathrm{B}+\mathrm{G}$ & $\mathrm{F}$ & $\mathrm{C}$ \\
\hline & & 6 & PKN15-2-1 & $\mathrm{DO}$ & $\mathrm{RB}$ & VF & $\mathrm{NC}$ \\
\hline & & 9 & PKN18-12-2 & $\mathrm{O}$ & $\mathrm{G}+\mathrm{Y}$ & VF & $\mathrm{C}$ \\
\hline & & 15 & PKQ03-9-2 & $\mathrm{O}$ & $\mathrm{B}+\mathrm{Y}$ & $\mathrm{F}$ & $\mathrm{C}$ \\
\hline & & 16 & PKQ03-2-3 & $\mathrm{O}$ & $\mathrm{B}+\mathrm{Y}$ & $\mathrm{R}$ & $\mathrm{C}$ \\
\hline & & 17 & PKQ04-2-3 & $\mathrm{DO}$ & $\mathrm{B}+\mathrm{Y}$ & FR & $\mathrm{C}$ \\
\hline II & 1 & 11 & PKN19-5-1 & DO & $G+Y$ & VF & $\mathrm{C}$ \\
\hline \multirow[t]{4}{*}{ III } & \multirow[t]{4}{*}{4} & 2 & PKN05-4-6 & $\mathrm{DO}$ & $\mathrm{B}+\mathrm{Y}$ & $\mathrm{F}$ & $\mathrm{C}$ \\
\hline & & 7 & PKN18-11-1 & $\mathrm{O}$ & $\mathrm{G}+\mathrm{Y}$ & $\mathrm{F}$ & $\mathrm{C}$ \\
\hline & & 10 & PKN19-3-1 & $\mathrm{RO}$ & $\mathrm{G}+\mathrm{Y}$ & VF & $\mathrm{C}$ \\
\hline & & 14 & PKN19-12-1 & DO & $\mathrm{B}+\mathrm{G} \& \mathrm{Y}$ & $\mathrm{F}$ & $\mathrm{C}$ \\
\hline \multirow[t]{5}{*}{ IV } & \multirow[t]{5}{*}{5} & 1 & PKN05-4-3 & $\mathrm{DO}$ & $\mathrm{G}+\mathrm{B}$ & $\mathrm{F}$ & $\mathrm{C}$ \\
\hline & & 8 & PKN18-11-2 & DO & $R B+G$ & F & $\mathrm{C}$ \\
\hline & & 12 & PKN19-8-1 & $\mathrm{RO}$ & $\mathrm{B}+\mathrm{G}$ & VF & $\mathrm{C}$ \\
\hline & & 13 & PKN19-8-3 & $\mathrm{LO}$ & $\mathrm{B}+\mathrm{Y}$ & $\mathrm{F}$ & $\mathrm{NC}$ \\
\hline & & 18 & PKQ09-2-2 & LO & $L Y+Y$ & $\mathrm{R}$ & $\mathrm{NC}$ \\
\hline
\end{tabular}

DO = Deep orange; RO = Reddish orange; $\mathrm{LO}=$ Light orange; $\mathrm{O}=$ Orange; $\mathrm{B}=$ Brown; $\mathrm{G}=$ Green; $\mathrm{Y}=$ Yellow; RB = Reddish brick; LY = Light yellow; VF = Very Flat; F = Flat; RF = Round flat; C = Crispy; NC = Non-crispy 
Table 2. Mean intra- (bold) and inter- cluster distances $\left(D^{2}\right)$ for the eighteen pumpkin genotypes obtained on the basis of the ten morphological characters

\begin{tabular}{lllll}
\hline \hline Clusters & I & II & III & IV \\
\hline I & 0.831 & 24.346 & 17.298 & 11.287 \\
II & - & 0.000 & 7.358 & 13.606 \\
III & - & - & 0.741 & 6.515 \\
IV & - & - & - & 0.651 \\
\hline \hline
\end{tabular}

Differences were observed in cluster means for almost all the ten characters in the 18 genotypes studied (Table 3). The eight genotypes in Cluster I showed a maximum mean value for fruit length $(15.88 \mathrm{~cm})$, fruit diametre $(23.12 \mathrm{~cm})$, individual fruit weight $(3.26 \mathrm{~kg})$, flesh thickness $(4.40 \mathrm{~cm})$ and maximum 98.12 days to $1^{\text {st }}$ female flowering.

The single genotype of cluster II produced the highest mean for fruit number per plant (17.00), TSS (10.00\%), fruit yield (51.00 t/ha) and mimimum incavity length $(5.00 \mathrm{~cm})$, cavity diametre $(10.00 \mathrm{~cm})$. It also had the second highest mean for flesh thickness $(4.00 \mathrm{~cm})$.

Four genotypes of cluster III had no highest mean values but scored second highest for fruit diametre $(19.75 \mathrm{~cm})$, fruit number/plant (10.50), individual fruit weight ( $2.17 \mathrm{~kg})$, fruit yield (36.00t /ha) and days to $1^{\text {st }}$ female flowering (94.75). Earliness is a desireable trait in pumpkins.

Five genotypes of cluster IV exhibited the second highest mean values for fruit length $(12.80 \mathrm{~cm})$ and second minimum values was for cavity length $(6.20 \mathrm{~cm})$, cavity diametre $(11.00 \mathrm{~cm})$. These genotypes were also the earliest, with a mean number of days to $1^{\text {st }}$ female flowering of 88.80 .

Based on principal component axes I and II, a twodimensional scattered plotting diagram $\left(\mathrm{Z}_{1}\right.$ and $\left.\mathrm{Z}_{2}\right)$ reflecting the position of genotypes are presented in Fig. 1. It is revealed from the diagram that there were mainly four clusters. Most distantly located clusters were cluster I [PKN12-5-2 (3), PKN12-5-4 (4), PKN151-1 (5), PKN15-2-1 (6), PKN18-12-2 (9), PKQ 03-92 (15), PKQ 03-2-3 (16), PKQ 04-2-3 (17)] and cluster II [PKN19-5-1 (11)]. Distribution pattern of genotypes in the scattered diagram also revealed that considerable variability exist in the studied germplasm.

The contribution of characters towards divergence of the genotypes is presented in Table 4. The results of the PCA revealed that in vector $I$, the important characters responsible for genetic divergence in the major axis of differentiation were fruit length (0.3806), fruit diameter (0.3819), individual fruit weight (0.3787), cavity length (0.3692), cavity diameter (0.3447), flesh thickness (0.2336), and days to $1^{\text {st }}$ female flowering (0.1510). Important traits in vector II (the second axis of differentiation) include cavity diameter (0.1058), fruit length (0.0520) and cavity length (0.0646). Quamruzzaman et al. (2008b) reported that days to $1^{\text {st }}$ male flower open, days to $1^{\text {st }}$ female flower open, fruit diameter, single fruit weight and fruits/plant contribute major portions of the total genetic diversity in ridge gourd. In another study Quamruzzaman et al. (2008a) reported fruits/plant and fruit yield/plant contribute towards divergence in bitter gourd. Masud et al. (1995) found that number of fruits/ plant and fruit yield/plant were important contributors to genetic divergence in pumpkin.

Table 3. Class mean values of 10 characters in 18 genotypes of pumpkin

\begin{tabular}{|c|c|c|c|c|}
\hline \multirow[t]{2}{*}{ Characters } & \multicolumn{4}{|c|}{ Clusters } \\
\hline & I & II & III & IV \\
\hline Days to $1^{\text {st }}$ female flowering & 98.12 & 98.00 & 94.75 & 88.80 \\
\hline Fruit length $(\mathrm{cm})$ & 15.88 & 11.00 & 12.50 & 12.80 \\
\hline Fruit diameter (cm) & 23.12 & 18.00 & 19.75 & 18.80 \\
\hline Fruit number/plant & 5.00 & 17.00 & 10.50 & 7.80 \\
\hline Individual fruit weight (kg) & 3.26 & 1.80 & 2.17 & 1.92 \\
\hline Cavity length (cm) & 8.50 & 5.00 & 6.87 & 6.20 \\
\hline Cavity diameter (cm) & 15.38 & 10.00 & 11.38 & 11.00 \\
\hline Flesh thickness (cm) & 4.40 & 4.00 & 3.70 & 3.30 \\
\hline TSS (\%) & 9.38 & 10.00 & 8.75 & 9.10 \\
\hline Fruit yield (t/ha) & 20.05 & 51.00 & 36.00 & 23.94 \\
\hline
\end{tabular}




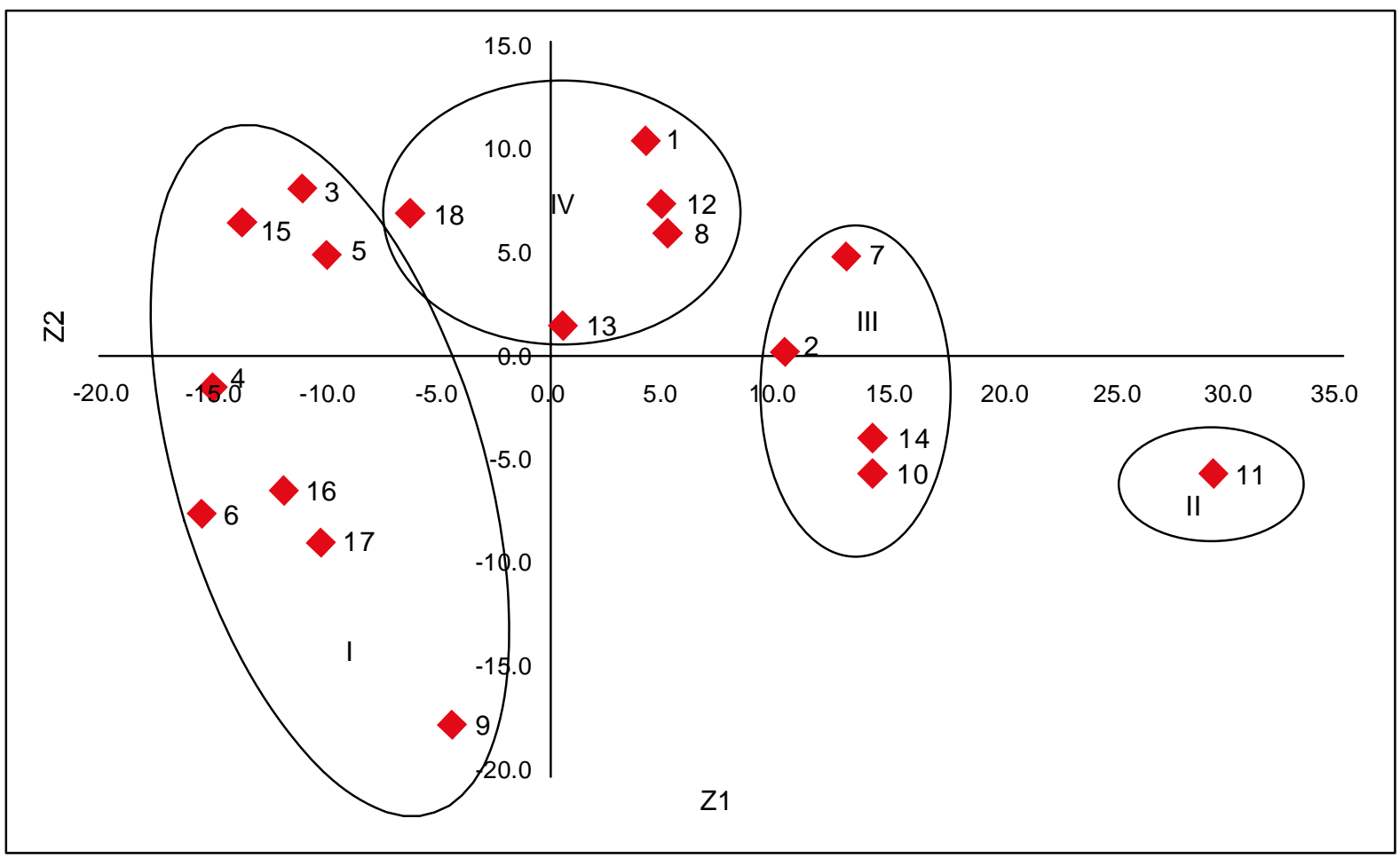

Fig. 1. Scatter distribution of 18 pumpkin genotypes on principle component score superimposed with clustering.

Generally crosses involving parents belonging to the most divergent clusters are expected to give maximum heterosis and create wide variability in genetic architecture. However, for a practical plant breeder, the objective is not only obtaining high heterosis but also to achieve high level of production within the shortest possible time. In the present study, the maximum distances existed between cluster I and cluster II, but very low number of fruits/plant and fruit

Table 4. Latent vectors for 10 principal component characters of 18 genotypes in pumpkin

\begin{tabular}{|c|c|c|}
\hline Characters & Vector $\left(Z_{1}\right)$ & Vector $\left(Z_{2}\right)$ \\
\hline Days to $1^{\text {st }}$ female flowering & 0.1510 & -0.6756 \\
\hline Fruit length $(\mathrm{cm})$ & 0.3806 & 0.0520 \\
\hline Fruit diameter (cm) & 0.3819 & -0.1552 \\
\hline Fruit number & -0.3714 & -0.3045 \\
\hline Individual fruit weight (kg) & 0.3787 & -0.0636 \\
\hline Cavity length (cm) & 0.3692 & 0.0646 \\
\hline Cavity diameter (cm) & 0.3447 & 0.1058 \\
\hline Flesh thickness (cm) & 0.2336 & -0.5188 \\
\hline TSS (\%) & -0.0264 & -0.0623 \\
\hline Fruit yield (t/ha) & -0.3079 & -0.3628 \\
\hline
\end{tabular}

yield were obtained in cluster I, while cluster III had higher number of fruits/plant as well as high fruit yield. Considering group distance and other agronomic performance, the inter-genotypic crosses between the members of cluster II with that of cluster III would exhibit considerable heterosis and are also likely to produce new recombinants with desired traits. Therefore, more emphasis should be given on cluster II and III in selecting inbreds for crossing in pumpkin hybridization programmes.

\section{References}

Arunachalam, V. 1981. Genetic distances in plant breeding. Indian Journal of Genetics, 41: 226-236.

BBS. 2008. Year Book of Agricultural Statistics, 149 pp. Bangladesh Bureau of Statistics, Ministry of Planning, Dhaka, Bangladesh.

Mahalanobis, P.C. 1936. On the the generalized distance in Statistics. In: Proceedings of the National Institute of Science, India, 2: 49-55.

Masud, M.A.T., Chowdhury, M.A.Z., Hossain, M.A. Hossain, S.M.M. 1995. Multivariate analysis in pumpkin (Cucurbita moschata Dueh ex Poir). Bangladesh Journal of Plant Breeding and 
Genetics, 8: 45-50.

Quamruzzaman, A.K.M., Rashid, M.A., Ali, M.M., Alam, A.K.M.M., Rahman, M.M. 2008a. Genetic diversity in bitter gourd (Momordica charantia L.). Bangladesh Journal of Agricultural Research, 33: 129-134.

Quamruzzaman, A.K.M., Rahman, M. H., Nazrul, I., Md., Rahman, S.M. L., Sarker, B.C. 2008b. Genetic diversity in land races of ridge gourd. Bangladesh Research Publication Journal, 1: 5-8.

Rao, C.R. 1952. Advanced Statistical Methods in Biometrical Research, 378 pp., John Wiley and Sons, New York, USA.

Singh, R.K., Chaudhury, B.D. 1985. Biometrical Methods in Quantitative Genetic Analysis, 318 pp. Kalyani Publishers, New Delhi, India. 